\title{
A meta-analysis of the cross-cultural psychometric properties of the Screen for Child Anxiety Related Emotional Disorders (SCARED)
}

\author{
William W. Hale III, ${ }^{1}$ Elisabetta Crocetti, ${ }^{2}$ Quinten A.W. Raaijmakers, ${ }^{1}$ \\ and Wim H.J. Meeus ${ }^{1}$ \\ ${ }^{1}$ Research Center Adolescent Development at Utrecht University, The Netherlands; ${ }^{2}$ Department of Educational \\ Sciences, University of Macerata, Italy
}

\begin{abstract}
Background: Accumulating studies have demonstrated that the Screen for Child Anxiety Related Emotional Disorders (SCARED), a modern youth anxiety questionnaire with scales explicitly designed to map onto specific DSM-IV-TR anxiety disorders, has good psychometric properties for children and adolescents from various countries. However, no study has yet been conducted as to the overall strength of the psychometric properties found in these studies. Methods: Studies were collected from the PsycINFO, PubMed, SSCI, SCI-Expanded, ERIC, and A\&HCI databases from the year of the SCARED's first publication (1997) to the present. The inclusion criteria focused on all studies that examined the psychometric properties of the SCARED. Results: We retained 21 articles, reporting a total of 25 studies from predominately Europe (Belgium, Germany, Italy, the Netherlands) and the USA, as well as South Africa and China, which matched our inclusion criteria. It was found that the psychometric properties were robust for the SCARED scales related to the symptoms of DSM-IV-TR anxiety disorders, that females scored significantly higher than males and that age had a moderating effect on male and female score differences. Conclusions: This meta-analysis suggests that the SCARED can be utilized as a screening instrument for DSM-IV-TR anxiety disorder symptom dimensions for children and adolescents from various countries. Keywords: Adolescents, anxiety, children, cross-cultural, meta-analysis, SCARED. Abbreviation: SCARED: Screen for Child Anxiety Related Emotional Disorders.
\end{abstract}

While structured psychiatric interviews are clearly one of the best instruments that psychiatrists and other mental health professionals have in diagnosing psychiatric disorders in children and adolescents, it is not the only instrument in their arsenal. Since structured psychiatric interviews can be quite time consuming to conduct and score, questionnaires can first be deployed as screening instruments to determine whether more detailed clinical interviews should be subsequently employed. Compared to clinical interviews, most psychiatric screening questionnaires can be administered and scored quite quickly.

With respect to the determination of anxiety disorder symptoms in children and adolescents, many such anxiety questionnaires exist. However, it may not always be clear to the clinician which anxiety questionnaire can be best used for screening anxiety disorder symptoms in children and adolescents. While literature reviews have tried to answer this question (e.g., Myers \& Winters, 2002), very few meta-analyses of anxiety questionnaires for anxiety disorder symptoms in children and adolescents have been conducted to supplement the findings of these literature reviews (a notable exception is a study by Seligman, Ollendick, Langley, \& Bechtoldt-Baldacci, 2004). This study will therefore help fill this omission

Conflict of interest statement: No conflicts declared. in the literature by conducting a meta-analysis on a well-known and frequently researched questionnaire for anxiety disorder symptoms in children and adolescents, the Screen for Child Anxiety Related Emotional Disorders (SCARED; Birmaher et al., 1997).

Some researchers have questioned whether a literature review is the best manner in which to judge the psychometric properties of a questionnaire. For example, in a study by Seligman et al. (2004), the authors argued that questionnaire recommendations from literature reviews are open to interpretation since literature reviews use a more general approach as opposed to meta-analysis that uses quantitative statistical analyses to focus on one individual, widely used questionnaire. Specifically, Seligman and colleagues (2004) suggest that literature reviews of questionnaires do not provide explicit criteria in the selection of studies used in determining the ultimate recommendations of such literature reviews and, therefore, 'are limited in their ability to synthesize the area in a systematic, unbiased way that proves useful to researchers and clinicians who use these instruments as part of a diagnostic assessment or to monitor changes in response to treatment' (p. 558). In other words, the selection and inclusion of studies in a literature review may not always be easily replicated by other researchers, nor does a literature review provide unbiased dataanalysis that other researchers could duplicate. 
Therefore, a meta-analysis of the psychometric properties of an instrument that has been recommended by a literature review can help to further support the claims made by this literature review.

With respect to specific advantages that metaanalysis studies have when compared to literature reviews, Gliner, Morgan, and Harmon (2003) point out four advantages: the providing of a summary statistic (i.e., the effect size) for the overall strength of a relationship; a demonstration of the reliability of a finding over multiple studies; increasing the power statistical power of these combined findings through increased sample sizes, thereby reducing Type II error possibilities; and increasing the external validity by introducing more variation by means of the larger sample sizes.

As just noted, while many anxiety questionnaires for the screening of anxiety disorder symptoms in children and adolescents exist, not all youth anxiety questionnaires are designed in the same manner. Prior to the mid 1990s, most child and anxiety questionnaires were global and one-dimensional in scope, hence their scale scores could not be related to specific anxiety disorder symptoms (Muris, Merckelbach, Schmidt, \& Mayer, 1999a). The only previous meta-analysis of the psychometric properties of child and adolescent anxiety questionnaires (Seligman et al., 2004) analyzed three questionnaires that had global scales that are not directly related to specific DSM-IV-TR anxiety disorder symptoms.

In contrast to these older scales, modern youth anxiety questionnaires employed multidimensional scales explicitly designed to map onto specific DSMIV-TR (American Psychiatric Association, 2000) based anxiety disorder symptom dimensions. In a review of the literature, Myers and Winters (2002) suggest that two of the better multidimensional questionnaires are the SCARED and the Multidimensional Anxiety Scale for Children (MASC; March, Parker, Sullivan, Stallings, \& Conners, 1997). By way of comparison, four of the SCARED scales map directly onto specific DSM-IV-TR anxiety disorders (Generalized Anxiety Disorder [GAD], Panic Disorder [PD], Separation Anxiety Disorder [SAD], and Social Phobia [SP]). The fifth scale of the SCARED, School Anxiety [SA] or School Refusal, while a serious anxiety problem (Fremont, 2003), is not a DSM-IV-TR anxiety disorder. The MASC takes a slightly different approach by having three of its scales measure physical symptoms, social anxiety and harm avoidance, scales that can be indirectly related to the generalized anxiety disorder and social phobia anxiety disorders of the DSM-IV-TR. Its final scale, Separation Anxiety Disorder, is directly related to the DSM-IV-TR anxiety disorder. Therefore, the SCARED may be a more appropriate instrument to screen for DSM-IV-TR anxiety disorders, whereas the MASC may be a more appropriate instrument to measure broader anxiety dimensions.
According to Myers and Winters (2002), the advantages that these two newer questionnaires hold over previous questionnaires are that "both the MASC and SCARED tap clear constructs, [and] have adequate initial psychometric properties' (p. 652). Furthermore, in studies by Muris and colleagues, it has been shown that the SCARED is strongly correlated with MASC (Muris, Gadet, Moulaert, \& Merckelbach, 1998) and the anxiety disorders section of the Diagnostic Interview Schedule for Children (Muris, Merckelbach, Mayer, \& Prins, 2000).

In this study, we will examine the psychometric properties of the SCARED by means of a metaanalysis. An important reason for conducting this meta-analysis is the accumulating studies that have shown the SCARED to have good psychometric properties for children and adolescents from various cultures. While the literature review of Myers and Winters (2002) synthesized various studies demonstrating adequate initial psychometric properties of the SCARED, several more studies have been conducted since the publication of their literature review that are supportive of this stand. However, no study has yet been conducted as to the overall combined strength of these various measures with regard to the cross-cultural psychometric properties of the SCARED. Therefore, in this meta-analysis we will examine the following four measures of the psychometric properties of the SCARED: a) the factor structure; b) the internal consistency of the five anxiety disorder symptom scales of the SCARED and the total SCARED score; c) the score differences between the various male and female children and adolescents that have been explored in prior studies; and d) the moderating effect that age might have on the score differences between male and female children and adolescents.

As previously mentioned, modern child and adolescent anxiety questionnaires purport to measure DSM-IV-TR anxiety disorder symptom dimensions. While many studies from various Western countries have borne out the SCARED's five anxiety disorder symptom scale factors, as well as demonstrating good internal consistencies, no one has yet explored the relative strength of these factor analyses and internal consistencies analyses when compared to one another. Strong meta-analysis findings would help to demonstrate the reliability and the external validity of the SCARED.

Another manner in which the reliability and external validity of the SCARED can be measured is with respect to score differences between the various child and adolescent age and sex cohorts. With respect to sex, studies have demonstrated that girls run a higher risk of developing anxiety disorders than boys (Cohen et al., 1993). Other studies have noted that girls experience more anxiety symptoms than boys (Ollendick \& King, 1994). Age also plays a moderating role in child and adolescent anxiety. For example, although SAD symptoms decrease as youth 
grow older (Cohen et al., 1993), other anxiety symptoms, such as GAD, increase as youth age (Rapee, 1991). Cross-cultural studies of these sex and age differences in anxiety symptoms have found similar findings (e.g., Crocetti, Hale, Fermani, Raaijmakers, \& Meeus, 2009; Dong, Yang, \& Ollendich, 1994; Essau, Leung, Conradt, Cheng, \& Wong, 2008; Li, Ang, \& Lee, 2008; Varela, SanchezSosa, Biggs, \& Luis, 2008). Therefore, analyses of sex differences and analyses of the moderating effect that age might have on the score differences between male and female children and adolescents that agree with previous anxiety studies would also help to demonstrate the cross-cultural external validity of the SCARED.

\section{Method}

\section{Selection of studies}

In December 2009 we searched for empirical studies explicitly focusing on the psychometric properties of the SCARED. Thus, our inclusion criteria focused on studies that examined the factor structure of the SCARED in either community or clinical samples of children and/or adolescents, and evaluated the convergent and discriminant validity ${ }^{1}$ of the SCARED. Five search strategies were used to systematically collect studies. First, in the electronic database PsycINFO we used the option 'Find citing articles': in this way we searched for any articles that cited Birmaher et al.'s article (1997) in which the SCARED was first introduced. We also searched for any articles that included the SCARED in either the title or the abstract. These were our inclusion criteria. Second, we repeated this search method through other relevant databases, specifically PubMed (US National Library of Medicine), SSCI (Social Science Citation Index), SCI-Expanded (Science Citation Index Expanded), ERIC (Education Resource Information Center), and A\&HCI (Arts \& Humanities Citation Index). Third, we searched the websites of journals deemed most likely to publish anxiety studies involving children and adolescents if they had published ahead-of-print articles that matched our inclusion criteria. Specifically, these journals were: Anxiety, Stress and Coping; Behaviour Research and Therapy; British Journal of Clinical Psychology; Depression and Anxiety; Journal of the American Academy of Child and Adolescent Psychiatry; Journal of Anxiety Disorders; Journal of Behavior Therapy and Experimental Psychiatry; Journal of Child Psychology and Psychiatry; Personality and Individual Differences. Fourth, the references of the collected journal articles were searched for further relevant studies. The only

\footnotetext{
${ }^{1}$ Convergent validity refers to the similarity of the results of the anxiety symptom dimensions obtained by the SCARED to the results of the anxiety symptom dimensions obtained by a similar DSM-IV-TR screening instrument. Discriminant validity refers to the sensitivity of the SCARED to differences of a specific anxiety symptom dimension scale severity between groups (e.g., boys and girls) and for differences between the five specific anxiety symptom dimension scales of the SCARED.
}

exclusion criterion was if the article was not an English language publication, although the SCARED could have been administered in any language for the research of this English-language publication. This search procedure was conducted separately by the first and second authors. A comparison of these separate searches by the first and second authors resulted in a strongly overlapping list of references (kappa > .95).

We retained 21 articles, reporting a total of 25 studies, which matched our inclusion criteria. These studies were of child and adolescent populations from the USA, Europe (Belgium, Germany, Italy, the Netherlands), South Africa, and China. These studies reported information about three different versions of the SCARED (see Table 1): the 38-item version of the SCARED originally developed by Birmaher et al. (1997); the 41-item version of the SCARED later proposed by Birmaher et al. (1999), which differs from the previous version as it has three additional items in the SP scale; and the 66-item version of the SCARED (which has been renamed the SCARED-Revised, or SCARED-R), which includes the PD, GAD, SP, and SAD scales (the SA items are grouped into the SAD scales in this version of the SCARED) (Muris, Merckelbach, van Brakel, Mayer, \& van Dongen, 1998b). This 66-item version also includes other anxiety disorder symptom scales that were not included in this meta-analysis since our focus was only on the anxiety scales common to all three SCARED versions.

We found that only one study (Wang et al., 2002) had matched our inclusion criteria, but fell within our exclusion criterion, since it was a publication in a language other than English.

\section{Data extraction}

An SPSS file was prepared and imputed with data from selected studies. In particular, we extracted the following information: 1) year of publication of the study; 2) type of population (clinical or community); 3) country in which the study was conducted; 4) sample size; 5) number of males and females; 6) mean age and standard deviation of the sample; 7) version of SCARED used; 8) data about factor structure of the SCARED (i.e., method used: exploratory factor analysis and/or confirmatory factor analysis; number of factors extracted; percentages of explained variance and/or fit indices; Cronbach alphas for each SCARED anxiety disorder symptom scale factor and for the total score; factor loadings for each SCARED item); 9) male and female means and standard deviations for each SCARED anxiety disorder symptom scale factor and for the total score.

\section{Data analysis}

First, we examined results about factor structure of the SCARED and we performed six meta-analyses (i.e., one for each SCARED anxiety disorder symptom scale factor as well as the SCARED total score) on alpha reliability coefficients. These analyses were conducted in SPSS following Rodriguez and Maeda's (2006) guidelines. For each scale we calculated the mean Cronbach alpha and its $95 \%$ confidence interval. Moreover, we reported the minimum and maximum values. 
Table 1 Studies included in the meta-analysis

\begin{tabular}{|c|c|c|c|c|c|c|c|c|c|}
\hline \multirow[b]{2}{*}{ Source (year) } & \multirow[b]{2}{*}{$\begin{array}{l}\text { Type of } \\
\text { population }\end{array}$} & \multirow[b]{2}{*}{$\begin{array}{l}\text { Country } \\
\text { of study }\end{array}$} & \multirow[b]{2}{*}{$\begin{array}{l}\text { Sample } \\
\text { size }\end{array}$} & \multirow[b]{2}{*}{$\begin{array}{l}\text { Sex \% } \\
\text { Males }\end{array}$} & \multicolumn{2}{|r|}{ Age } & \multicolumn{3}{|c|}{$\begin{array}{l}\text { Examination of SCARED factor } \\
\text { structure }\end{array}$} \\
\hline & & & & & Range & $\begin{array}{l}\text { Mean } \\
\text { (SD) }\end{array}$ & $\begin{array}{l}\text { Version of } \\
\text { the SCARED }\end{array}$ & Method & $\begin{array}{l}\text { Number } \\
\text { of factors }\end{array}$ \\
\hline Birmaher et al. (1997) & Clinical & USA & 341 & 40.47 & $9-18$ & $14.50(2.30)$ & 38 items & EFA & 5 \\
\hline Birmaher et al. (1999) & Clinical & USA & 190 & 48.42 & $9-19$ & $13.80(2.50)$ & 41 items & EFA & 5 \\
\hline Boyd et al. (2003) & Community & USA & 111 & 48.65 & $14-19$ & 15.75 (1.19) & 41 items & CFA; EFA & 3 \\
\hline Crocetti et al. (2009) & Community & Italy & 1975 & 45.67 & $11-19$ & $14.50(2.40)$ & 38 items & CFA & 5 \\
\hline Essau et al. (2002) & Community & Germany & 556 & 49.46 & $8-12$ & $10.60(1.20)$ & 41 items & EFA & 5 \\
\hline Hale et al. (2005) & Community & The Netherlands & 1340 & 48.13 & $10-18$ & $14.39(2.20)$ & 38 items & CFA & 5 \\
\hline Monga et al. (2000) & Clinical & USA & 295 & 43.05 & 9-19 & $14.40(2.30)$ & 38 items & N/A & 5 \\
\hline \multicolumn{10}{|l|}{ Muris et al. (1998a) } \\
\hline Study I & Community & The Netherlands & 75 & 56 & $9-12$ & $10.40(.90)$ & 66 items & N/A & 4 \\
\hline Study II & Community & The Netherlands & 120 & 48.33 & $8-13$ & $10.70(1.00)$ & 66 items & N/A & 4 \\
\hline \multicolumn{10}{|l|}{ Muris et al. (1998b) } \\
\hline Study I & Community & The Netherlands & 68 & 44.12 & $8-12$ & $10.10(1.30)$ & 66 items & $\mathrm{N} / \mathrm{A}$ & 4 \\
\hline Study II & Community & The Netherlands & 81 & 59.26 & $8-13$ & $10.40(1.20)$ & 66 items & N/A & 4 \\
\hline Muris et al. (1999a) & Community & The Netherlands & 674 & 48.96 & $8-13$ & $10.28(1.22)$ & $\begin{array}{l}66 \text { items } \\
38 \text { items }\end{array}$ & $\begin{array}{l}\text { EFA } \\
\text { CFA }\end{array}$ & 5 \\
\hline \multicolumn{10}{|l|}{ Muris et al. (1999b) } \\
\hline Study I & Community & The Netherlands & 101 & 46.53 & $11-14$ & $12.20(.50)$ & 66 items & $\mathrm{N} / \mathrm{A}$ & 4 \\
\hline Study II & Community & The Netherlands & 71 & 50.70 & $8-12$ & $9.60(1.10)$ & 66 items & N/A & 4 \\
\hline Study III & Community & The Netherlands & 88 & 61.36 & $8-12$ & $10(1.20)$ & 66 items & N/A & 4 \\
\hline Muris et al. (2001a) & Community & The Netherlands & 534 & 44 & $7-14$ & $10.10(1.50)$ & 66 items & N/A & 4 \\
\hline $\begin{array}{l}\text { Muris \& Steerneman } \\
(2001 \mathrm{~b})\end{array}$ & Clinical & The Netherlands & 48 & 54.17 & $8-17$ & $12.80(2.47)$ & 66 items & $\mathrm{N} / \mathrm{A}$ & 4 \\
\hline Muris et al. (2002a) & Community & Belgium & 521 & 46.06 & $12-18$ & $15.10(2.00)$ & 41 items & $\mathrm{N} / \mathrm{A}$ & 5 \\
\hline Muris et al. (2002b) & Community & South Africa & 609 & 52.38 & $8-13$ & $10.70(1.60)$ & 41 items & EFA & 4 \\
\hline Muris et al. (2004) & Clinical & The Netherlands & 242 & 57.85 & $7-17$ & $12(2.9)$ & 66 items & N/A & 4 \\
\hline Muris et al. (2006) & Community & South Africa & 701 & 47.65 & $8-18$ & $12.28(1.47)$ & 41 items & EFA & 5 \\
\hline Ogliari et al. (2006) & Community & Italy & 756 & 46.96 & $8-17$ & $13.03(2.60)$ & 41 items & EFA & 4 \\
\hline Su et al. (2008) & Community & China & 1559 & 49.65 & $8-16$ & $11.80(2.10)$ & 41 items & EFA; CFA & 5 \\
\hline Wren et al. (2004) & Community & USA & 236 & 49.15 & $8-13$ & $10.54(1.47)$ & 41 items & N/A & 5 \\
\hline Wren et al. (2007) & Community & USA & 515 & 49.13 & $8-13$ & $10.50(1.40)$ & 41 items & EFA & 4 \\
\hline
\end{tabular}

Note: $\mathrm{CFA}=$ confirmatory factor analysis; $\mathrm{EFA}=$ exploratory factor analysis; $\mathrm{N} / \mathrm{A}=$ not available.

Second, by using a meta-analytic approach we compared sex differences on anxiety across studies (Lipsey \& Wilson, 2001). We performed one meta-analysis for each SCARED factor by means of Comprehensive MetaAnalysis (CMA) software (Version 2.2.048) (Borenstein, Hedges, Higgins, \& Rothstein, 2008). Pertinent data were imputed in CMA by copying them from the SPSS file. For each scale we calculated an effect size: the standardized difference between the means of two groups (Cohen's d). According to Cohen's (1988) criteria, $.20 \leq d<.50$ are considered small effects, $.50 \leq$ $d<.80$ are considered moderate effects, and $.80 \leq d$ are considered large effects. Effect sizes indicating that females reported higher anxiety scores than males received a positive sign. We also computed 95\% confidence intervals around the point estimate of each set of effect sizes. Since age was a continuous variable, its moderating effect on sex differences was tested in CMA by means of meta-regressions.

Finally, we conducted two publication bias analyses available in CMA to control for the fact that published studies have a larger mean effect size than unpublished studies (Rothstein, Sutton, \& Borenstein, 2005). First, we used the trim and fill procedure; this procedure is a nonparametric statistical technique that evaluates the effect of potential data censoring on the result of the meta-analyses (Duval \& Tweedie, 2000). Adopting this procedure, a funnel plot is constructed of each study's effect size against the sample size or the standard error. These plots should be shaped as a funnel if no data censor is present. Nevertheless, since smaller or nonsignificant studies are less likely to be published, studies in the bottom left-hand corner of the plot are often omitted. In our case, the $k$ rightmost studies considered to be symmetrically unmatched were trimmed. The trimmed studies were then replaced and their missing counterparts imputed or filled as mirror images of the trimmed outcomes. This allows for the computation of an adjusted effect size and the 95\% confidence interval. Second, a fail-safe number was computed for each SCARED scale meta-analysis. This number estimates the number of studies with non-significant findings necessary to make the combined effect size non-significant. Rosenthal (1979) proposed a fail-safe $N$ higher than $(5 k+10)$ as supporting findings' robustness (where $k$ refers to the number of studies included in the meta-analysis).

\section{Results}

\section{SCARED factor structure and scale reliabilities}

Twelve of the 25 studies included in this metaanalysis examined the SCARED factor structure. This examination of the factor structure can be 
conducted in two ways: either by exploratory factor analysis, which is literally an exploration of how many factors a questionnaire is composed of, or by confirmatory factor analysis, which tests if the theoretic factors of a questionnaire can be confirmed (Byrne, 2001). Two studies analyzed the factor structure only by means of confirmatory factor analysis (CFA), seven examined the factor structure only by means of exploratory factor analysis (EFA), and three studies conducted both EFA and CFA analyses (see Table 1).

With respect to the five studies that used CFA to analyze the factor structure, four supported the fivefactor structure (i.e., GAD, PD, SA, SAD, and SP), whereas only one found support for a three-factor structure (GAD, PD, and SP). For the 10 studies that analyzed the factor structure using EFA, six found support for the five-factor solution hypothesized by Birmaher et al. (1997) and reported percentage of explained variance lay between $36.32 \%$ and $39.49 \%$. Additionally, three studies found a four-factor solution (for the four DSM-IV-TR anxiety symptom dimension scales [GAD, PD, SAD, and SP] but without the SA scale) and reported percentage of explained variance lay between $32.70 \%$ and $37.05 \%$. And finally, one study found only a three-factor solution (GAD, PD, and SP) with a reported percentage of explained variance of $26.45 \%$.

Furthermore, the mean factor loadings for each individual SCARED scale was calculated from the studies referred to in Table 1. From these analyses, the following mean factor loadings were found: for the mean factor loading PA was $.57(S D=.06$; range .46-.67); for GAD it was $.57(S D=.07$; range .47$.65)$; for $\mathrm{SA}$ it was $.55(S D=.08$; range $.40-.65)$; for SAD it was $.53(S D=.05$; range .44-.59); and for SP it was $.65(S D=.07$; range $.58-.78)$.

Meta-analyses on coefficient alphas performed for each SCARED factor revealed that high-reliability alpha scores were reported for the GAD, PA, SAD, and SP scales across the studies, and somewhat lower-reliability alpha scores for the SA scale. Additionally, the reliability alpha scores for the SCARED total score were found to be excellent, both for the 38 -item and the 41-item version of the SCARED (see Table 2). ${ }^{2}$

Overall, from these findings it would appear that there is strong evidence for the GAD, PA, SAD, and SP scales, which are purported to map onto DSM-IVTR anxiety disorder dimensions, but somewhat less support for the SA scale, which is not directly related to a specific DSM-IV-TR anxiety disorder dimension.

\footnotetext{
2 Only the total score for the 38-item version and the 41-item version of the SCARED were analyzed, since the total score for the 66-item version of the SCARED also includes other anxiety disorder symptom scales that were not included in this meta-analysis since our focus was only on the anxiety scales common to all the three versions of the SCARED.
}

Table 2 Meta-analytic results of analyses of coefficient alphas of the SCARED scales

\begin{tabular}{|c|c|c|c|c|c|c|}
\hline \multirow[b]{2}{*}{ Scale } & \multirow[b]{2}{*}{$k$} & \multirow{2}{*}{$\begin{array}{c}\text { Mean } \\
\alpha\end{array}$} & \multicolumn{2}{|c|}{$95 \% \mathrm{CI}$} & \multirow[b]{2}{*}{ Minimum } & \multirow[b]{2}{*}{ Maximum } \\
\hline & & & Lower & Upper & & \\
\hline GAD & 20 & .81 & .78 & .83 & .71 & .78 \\
\hline PD & 20 & .84 & .80 & .87 & .70 & .92 \\
\hline SA & 9 & .62 & .53 & .70 & .43 & .76 \\
\hline \multicolumn{7}{|l|}{ SAD } \\
\hline Overall & 20 & .72 & .69 & .74 & .54 & .86 \\
\hline $\begin{array}{l}\text { Version with } \\
8 \text { items }\end{array}$ & 11 & .72 & .68 & .75 & .54 & .80 \\
\hline $\begin{array}{l}\text { Version with } \\
12 \text { items }\end{array}$ & 9 & .77 & .73 & .81 & .60 & .86 \\
\hline \multicolumn{7}{|l|}{ SP } \\
\hline Overall & 20 & .78 & .75 & .80 & .69 & .89 \\
\hline $\begin{array}{l}\text { Version with } \\
4 \text { items }\end{array}$ & 14 & .75 & .72 & .78 & .69 & .82 \\
\hline $\begin{array}{l}\text { Version with } \\
7 \text { items }\end{array}$ & 6 & .80 & .73 & .85 & .75 & .89 \\
\hline \multicolumn{7}{|l|}{ Total score } \\
\hline Overall & 10 & .91 & .89 & .92 & .89 & .93 \\
\hline $\begin{array}{l}\text { Version with } \\
38 \text { items }\end{array}$ & 3 & .91 & .84 & .96 & .89 & .93 \\
\hline $\begin{array}{l}\text { Version with } \\
41 \text { items }\end{array}$ & 7 & .91 & .89 & .91 & .89 & .91 \\
\hline
\end{tabular}

Note: $k=$ number of studies; $\mathrm{CI}=95 \%$ confidence interval. $\mathrm{GAD}=$ generalized anxiety disorder symptoms; $\mathrm{PD}=$ panic disorder symptoms; $\quad \mathrm{SA}=$ school anxiety symptoms; $\mathrm{SAD}=$ separation anxiety disorder symptoms; $\mathrm{SP}=$ social phobia symptoms.

\section{SCARED sex differences}

Of the 25 studies included in this meta-analysis, 18 included analysis of male and female child and adolescent score differences for the SCARED subscales (GAD, PD, SA, SAD, and SP) and 10 included analysis of male and female child and adolescent score differences for the SCARED total score (based on either the 38-item or 41-item version). In Figure 1, these scores differences are represented with an error-bar chart. For the four SCARED scales related to DSM-IV-TR anxiety disorder symptoms (GAD, PD, SAD, and SP), most all of the studies indicated that the females scored significantly higher than the males. A similar pattern of differences emerged for the SCARED total score. For the SA scale, the findings are less clear.

These findings, which are graphically represented in Figure 1, are supported by findings noted in Table 3. As the findings of Table 3 demonstrate, these meta-analyses findings of the SCARED anxiety factor effect sizes indicate that females scored significantly higher than males on all factors except for SA, on which no significant differences emerged. Similarly, females scored significantly higher than males on SCARED total score. With the exception of the SA scale, the effect sizes of the other four SCARED scales (GAD, PD, SAD, and SP) and of the SCARED total score were found to be small (Cohen, 1988). The varying versions of the SAD scale (8 items 

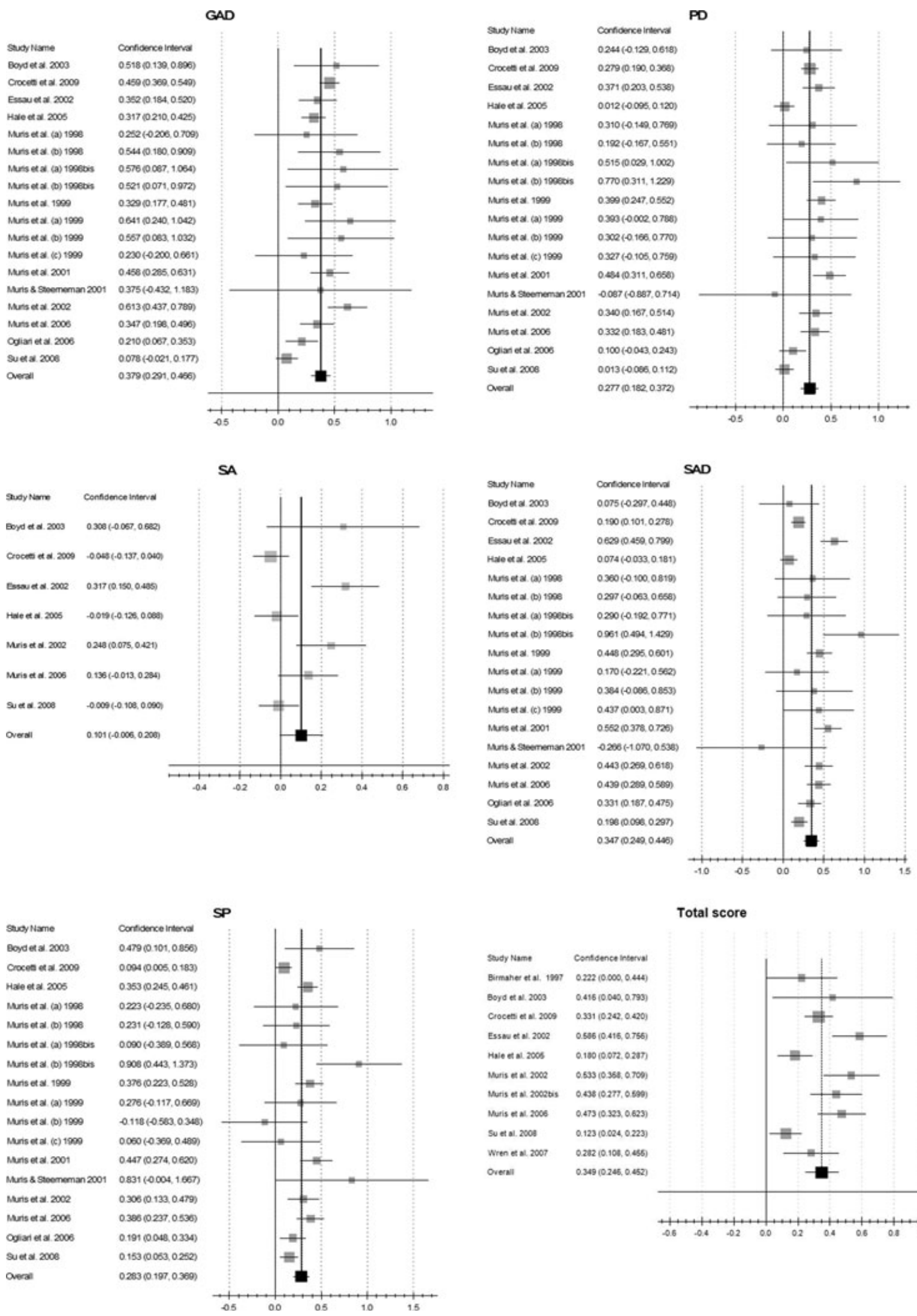

Total score

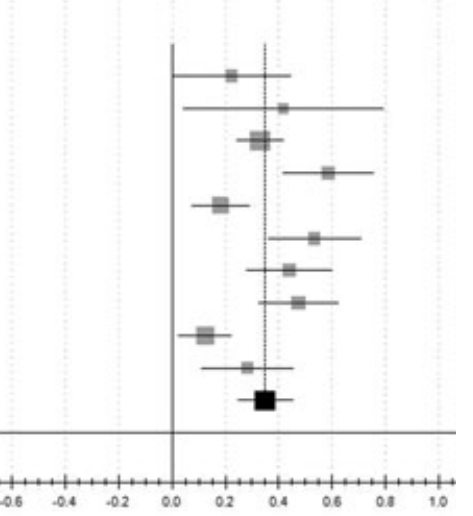

Figure 1 Meta-Analyses on the Sex Differences on the SCARED Scales.

Note: Error-bars represent 95\% confidence intervals (CIs). All studies reported in these graphs included community samples, except for the study by Muris and Steerneman (2001) who employed a clinical sample. The positive effect sizes indicate that females scored higher than males. The size of the square is proportional to the sample size of the corresponding study; larger sample sizes are represented by larger squares. GAD = Generalized Anxiety Disorder symptoms; $\mathrm{PD}=$ Panic Disorder symptoms; $\mathrm{SA}=$ School Anxiety symptoms; $\mathrm{SAD}=$ Separation Anxiety Disorder symptoms; $\mathrm{SP}=$ Social Phobia symptoms 
Table 3 Meta-analytic results of studies comparing sex differences on the SCARED scales

\begin{tabular}{lcrc}
\hline & $\begin{array}{c}\text { Number } \\
\text { of females- } \\
\text { Number } \\
\text { of males }\end{array}$ & $k$ & Size, $d(\mathrm{CI})$ \\
\hline Scale & $4887-4469$ & 18 & $.38^{* * *}(.29-.47)$ \\
GAD & $4887-4469$ & 18 & $.28^{* * *}(.18-.37)$ \\
PD & $3539-3224$ & 7 & $.10^{\mathrm{a}}(-01-.21)$ \\
SA & & & \\
SAD & $4887-4469$ & 18 & $.35^{* * *}(.25-.44)$ \\
Overall & $4284-3909$ & 9 & $.32^{* * *}(.20-.43)$ \\
Version with 8 items & $603-560$ & 9 & $.45^{* * *}(.33-.57)$ \\
Version with 12 items & & & \\
SP & $4887-4469$ & 18 & $.30^{* * *}(.21-.40)$ \\
Overall & $2715-2437$ & 12 & $.29^{* * *}(.17-.41)$ \\
Version with 4 items & $2172-2032$ & 6 & $.32^{* * *}(.18-.46)$ \\
Version with 7 items & & & \\
Total score & $4288-3930$ & 10 & $.34^{* * *}(.25-.45)$ \\
Overall & $1971-1675$ & 3 & $.26^{* * *}(.20-.33)$ \\
Version with 38 items & Effect \\
Version with 41 items & $2317-2255$ & 7 & $.40^{* * *}(.25-.55)$ \\
\hline
\end{tabular}

Note: $k=$ number of studies; $d=$ standardized mean difference (female scores - male scores); $\mathrm{CI}=95 \%$ confidence interval. ${ }^{* * *} p<.001{ }^{\mathrm{a}} p=.065$. GAD $=$ generalized anxiety disorder symptoms; $\mathrm{PD}=$ panic disorder symptoms; $\mathrm{SA}=$ school anxiety symptoms; $\mathrm{SAD}=$ separation anxiety disorder symptoms; $\mathrm{SP}=$ social phobia symptoms

vs. 12 items), the SP scale (4 items vs. 7 items), and the SCARED total score (38 items vs. 41 items) of the studies used in this meta-analysis (Table 1) did not influence the effect size findings reported in Table 3.

Furthermore, we tested by means of meta-regression analyses whether the effect sizes were moderated by a continuous variable, specifically the mean age of the child and adolescent samples. This is graphically represented in Figure 2. The analyses of the sex effect sizes as moderated by the age of the child and adolescent populations of this meta-analysis study revealed that all effect sizes (except for school anxiety; $B_{\text {age }}=-.03, n s$ ) were significantly moderated by the mean age of the sample. Specifically, the effect sizes for sex differences on PD $\left(B_{\text {age }}=-.03, p<.01\right)$, SAD $\left(B_{\text {age }}=-.06, p<.001\right)$, and SP $\left(B_{\text {age }}=-.03, p<.05\right)$ were lower in older adolescent samples, whereas the effect size for sex difference on GAD $\left(B_{\text {age }}=.03, p<.05\right)$ was higher in older adolescent samples. As a consequence of these contrasting trends (with effect sizes for sex differences on PD, SAD, and SP decreasing with age and effect size for sex differences on GAD increasing with age), the moderation effect of age on the SCARED total score was found to be non-significant $\left(B_{\text {age }}=.02, n s\right)$. It should be noted that no additional moderator analyses (such as including categorical variables as sample type [i.e., clinical vs. community sample] or country in which the study was conducted) could be performed since we did have enough studies to test for these moderators.

Additionally, no publication bias was found in any meta-analyses. The fail-safe number was $k=1042$ for $\mathrm{GAD}, k=506$ for $\mathrm{PD}, k=806$ for $\mathrm{SAD}, k=647$ for SP, and $k=507$ for the SCARED total score. All failsafe numbers were substantially higher than the minimum number required $(k=100$ for the SCARED scale scores and $k=60$ for the SCARED total score) when applying Rosenthal's formula (1979) to our meta-analyses to demonstrate the robustness of our findings.

\section{Discussion}

In this meta-analysis of the SCARED we have found that the four scales (GAD, PA, SAD, and $\mathrm{SP}$ ) related to the DSM-IV-TR anxiety disorders have proven to have robust psychometric properties and found somewhat less support for the fifth scale (SA), which is not related to a DSM-IV-TR anxiety disorder (Table 1). This finding was also mirrored by the internal consistency alpha scores (Table 2) and the effect size findings for the score differences between boys and girls (Table 3). Specifically, the score difference findings (Figure 1 and Table 3 ) between boys and girls indicated that the girls scored significantly higher than boys on the four DSM-IV-TR anxiety disorder scales factors and the SCARED total score, while no significant sex differences emerged for the SA scale. These findings of the sex differences mirrors that of other cross-cultural studies of child and adolescent anxiety symptoms (e.g., Crocetti et al., 2009; Dong et al., 1994; Essau et al., 2008; Li et al., 2008; Varela et al., 2008).

Additionally, it was demonstrated that age had a moderating effect on the score differences between the boys and girls for the four DSM-IV-TR anxiety disorder scale factors, while age did not have a moderating effect on the SA scale (Figure 2). The sex differences on $\mathrm{PD}, \mathrm{SAD}$, and SP anxiety symptoms decreased as children and adolescents grew older (Gullone, 2000), whereas there was a general increase in sex differences on GAD anxiety symptoms for the older participants.

While it is outside the scope of this article is discuss all the potential clinical implications of this study, this finding on GAD may be of interest for both researchers and clinicians. While previous researchers have noted a general increase in GAD during adolescence (Rapee, 2001), the present study agrees with previous studies that this increase predominantly applies to adolescent girls (Hale, Raaijmakers, Muris, Van Hoof, \& Meeus, 2008). GAD worry is strongly focused on interpersonal difficulties (Rapee, 2001), and previous studies have shown that interpersonal difficulties are associated specifically with GAD in adolescent girls (Hale, Engels, \& Meeus, 2006). Given the strong increase of GAD symptoms in girls, early interventions focused on strengthening social competence in dealing with interpersonal difficulties and on supplanting worry as a dysfunctional coping skill may help reduce the 

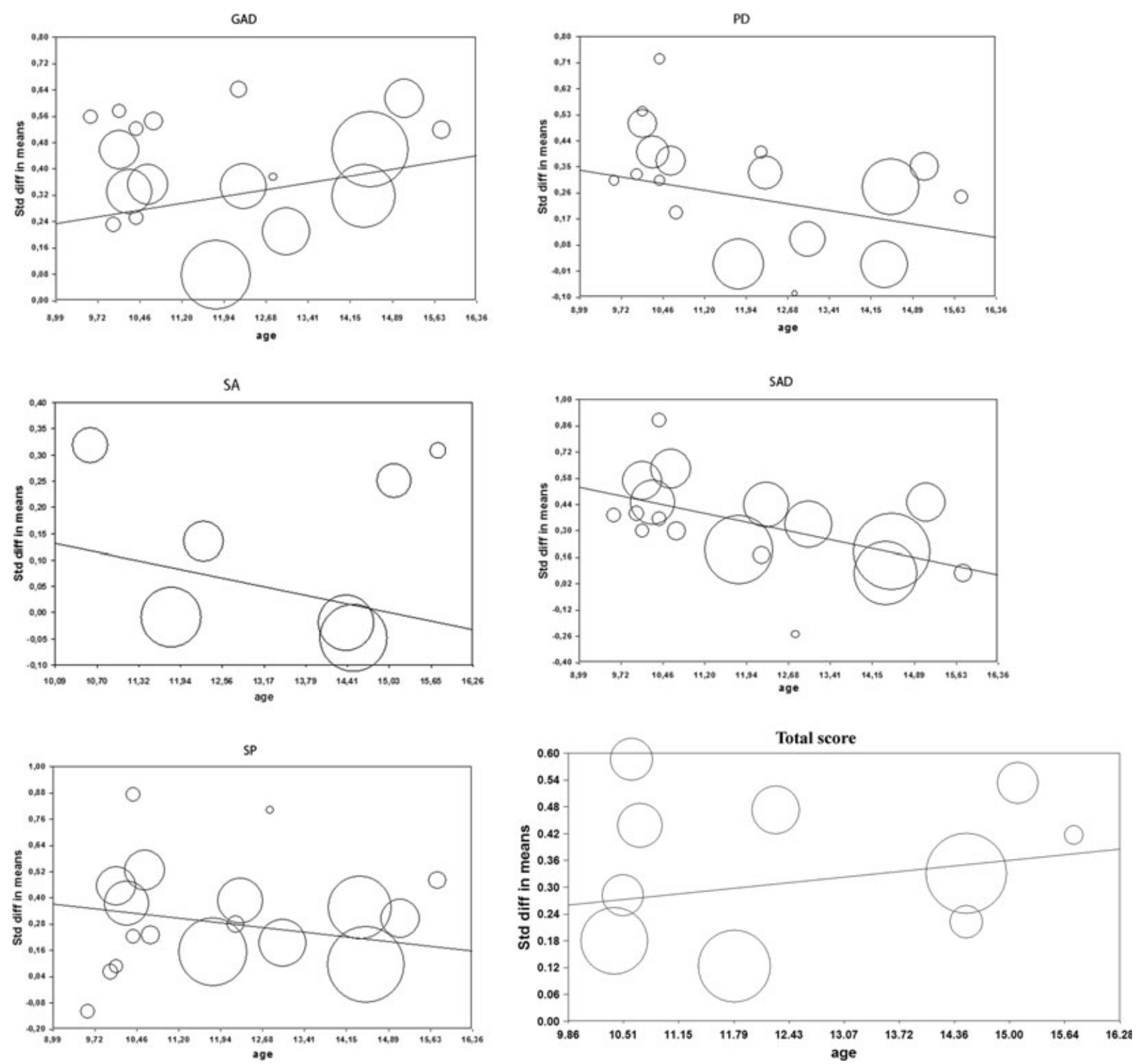

Figure 2 Meta-Regressions of Sex Effect Sizes on the SCARED Scales with Mean Age of the Sample Studies as a Moderator. Note: Each circle represents one study. The size of the circle is proportional to sample size of the related study: larger sample sizes are represented by larger circles. GAD = Generalized Anxiety Disorder symptoms; $\mathrm{PD}=$ Panic Disorder symptoms; $\mathrm{SA}=$ School Anxiety symptoms; SAD = Separation Anxiety Disorder symptoms; $\mathrm{SP}=$ Social Phobia symptoms

risk for later developmental maladaptation, as suggested by Bosquet and Egeland (2006). Future studies could be conducted to test whether such interventions in fact reduce these risks.

This meta-analysis analyzed 21 articles, for a total of 25 studies, of the psychometric properties of the SCARED from child and adolescent populations from the USA, Europe (Belgium, Germany, Italy, the Netherlands), South Africa, and China. So, at least with respect to the various cultures represented in this meta-analysis of children and adolescents who primarily came from the general community, these findings indicate that the DSM-IV-TR anxiety disorder symptoms would appear to consistently have similar pathogenic tendencies (at least when the SCARED is employed), a finding that might also be of interest to both researchers and clinicians. Since the five-factor version of the SCARED is a freely available questionnaire, these findings are even more impressive. Given that there was no one particular publishing corporation that determined the multilingual translation of these SCARED factor items, these multilingual translations of the SCARED were not field tested by a publisher before being employed in the included research studies. The high reliabilities (coefficient alphas), the consistent sex differences, and the moderating effect of age for the four DSM-IV-TR anxiety disorder factors are in agreement 
with other studies of child and adolescent anxiety disorder symptoms and help to demonstrate the robustness of these SCARED factors. Hence, it would appear that the SCARED lives up to its name, being a screening instrument with good psychometric properties for anxiety disorder symptoms in children and adolescents from various cultures.

In addition to these findings, some limitations of this study should be considered. One limitation could be the exclusion criterion of non-English-language publications. However, in our inclusion of articles for this meta-analysis we came across only one study published in a language other than English (the only exclusion criterion of this meta-analysis). A second limitation might be that while North America and the European continents were well represented, there were only two African studies (both from South Africa) and only one study from China. Hence, neither South American nor other Asian or African countries were included in these analyses.

Furthermore, no additional moderator analyses of the country in which the study was conducted could be performed since we did have enough studies to test the moderating effects of one country compared to another as some studies were conducted only once in a particular country. However, the SCARED is a relatively new instrument, first published in 1997, and it is quite conceivable that new psychometric property studies from other countries will appear in the future as well as repeated studies in the countries where it has only been conducted once, which would allow for such moderating effect analyses.

In conclusion, the findings of this meta-analysis would seem to indicate that the SCARED has robust psychometric properties and can utilized as a screening instrument for the DSM-IV-TR's generalized anxiety disorder, panic disorder, separation anxiety disorder, and social phobia symptoms, and, to a lesser extent, for school anxiety symptoms. The findings of this study help to demonstrate the usefulness of this brief screening questionnaire, which can be employed in cross-cultural settings. The SCARED may be a valuable addition to the psychiatric instrument batteries of psychiatrists and other professionals in related mental health fields.

\section{Acknowledgements}

This study was fully funded by the Research Center Adolescent Development at Utrecht University.

\section{Correspondence to}

William W. Hale III, Utrecht University, Research Center Adolescent Development, P.O. Box 80.140, 3508 TC Utrecht, The Netherlands; Tel: +31-302534650; Fax: +31-30-2532200; Email: b.hale@ uu.nl

\section{Key points}

- Recent studies have shown that the SCARED, a modern anxiety questionnaire, has good psychometric properties for children and adolescents.

- No study has yet been conducted as to the overall strength of the psychometric properties found in these studies of children and adolescent males and females from various cultures.

- This meta-analysis demonstrates that the psychometric properties of the SCARED are robust, that females scored significantly higher than males, and that age had a moderating effect on male and female score differences.

- The moderating effect of age on anxiety symptoms, particularly GAD symptoms increasing for older girls, may highlight the importance of early interventions to help reduce the risk for later developmental maladaptation.

- This meta-analysis suggests that the SCARED can be utilized in various countries as a cross-cultural screening instrument for DSM-IV-TR anxiety disorder symptom dimensions.

\section{References}

References marked with an asterisk (*) indicate studies included in the meta-analysis.

American Psychiatric Association. (2000). Diagnostic and statistical manual of mental disorders, 4th edition, text revision (DSM-IV-TR). Washington, DC: American Psychiatric Association.

*Birmaher, B., Brent, D.A., Chiappetta, L., Bridge, J., Monga, S., \& Baugher, M. (1999). Psychometric properties of the Screen for Child Anxiety Related Emotional Disorders (SCARED): A replication study. Journal of the
American Academy of Child and Adolescent Psychiatry, 38, 1230-1236.

*Birmaher, B., Khetarpal, S., Brent, D., Cully, M., Balach, L., Kaufman, J., \& Neer, S. M. (1997). The Screen for Child Anxiety Related Emotional Disorders (SCARED): Scale construction and psychometric characteristics. Journal of the American Academy of Child and Adolescent Psychiatry, 36, 545-553.

Borenstein, M., Hedges, L.V., Higgins, J.P.T., \& Rothstein, H.R. (2008). Comprehensive Meta-Analysis (Version 2.2.048) [Computer software]. Englewood, NJ: Biostat. 
Bosquet, M., \& Egeland, B. (2006). The development and maintenance of anxiety symptoms from infancy through adolescence in a longitudinal sample. Developmental Psychopathology, 18, 517-550.

*Boyd, R.C., Ginsburg, G.S., Lambert, S.F., Cooley, M.R., \& Campbell, K.D.M. (2003). Screen for Child Anxiety Related Emotional Disorders (SCARED): Psychometric properties in an African American parochial high school sample. Journal of the American Academy of Child and Adolescent Psychiatry, 42, 1188-1196.

Byrne, B.M. (2001). Structural Equation Modeling with AMOS. Mahwah, NJ: Lawrence Erlbaum Associates Inc.

Cohen, J. (1988). Statistical power analysis for the behavioral sciences. New York: Academic Press.

Cohen, P., Cohen, J., Kasen, S., Velez, C.N., Hartmark, C., Johnson, J., Rojas, M., Brooks, J., \& Streuning, E.L. (1993). An epidemiological study of disorders in late childhood and adolescence: I. Age and gender specific prevalence. Journal of Child Psychology and Psychiatry, 34, 851-867.

${ }^{*}$ Crocetti, E., Hale, W.W. III, Fermani, A., Raaijmakers, Q., \& Meeus, W. (2009). Psychometric Properties of the Screen for Child Anxiety Related Emotional Disorders (SCARED) in the general Italian adolescent population: A validation and a comparison between Italy and The Netherlands. Journal of Anxiety Disorders, 23, 824-829.

Dong, Q., Yang, B., \& Ollendich, T.H. (1994). Fears in Chinese children and adolescents and their relations to anxiety and depression. Journal of Child Psychology and Psychiatry, 35, 351-363.

Duval, S., \& Tweedie, R. (2000). A nonparametric 'trim and fill' method of accounting for publication bias in metaanalysis. Journal of the American Statistical Association, 95, 89-98.

Essau, C.A., Leung, P.W.L., Conradt, J., Cheng, H., \& Wong, T. (2008). Anxiety symptoms in Chinese and German adolescents: Their relationship with early learning experiences, perfectionism, and learning motivation. Depression and Anxiety, 25, 801-810.

*Essau, C.A., Muris, P., \& Ederer, E.M. (2002). Reliability and validity of the Spence Children's Anxiety Scale and the Screen for Child Anxiety Related Emotional Disorders in German children. Journal of Behavior Therapy and Experimental Psychiatry, 33, 1-18.

Fremont, W.P. (2003). School refusal in children and adolescents. American Family Physician, 68, 15551560.

Gliner, J.A., Morgan, G.A., \& Harmon, R.J. (2003). Metaanalysis: Formulation and interpretation. Journal of the American Academy of Child and Adolescent Psychiatry, 42, 1376-1379.

Gullone, E. (2000). The development of normal fear: A century of research. Clinical Psychology Review, 20, 429-451.

Hale, W.W. III, Engels, R., \& Meeus, W. (2006). Adolescents' perceptions of parenting behaviours and its relationship to adolescent generalized anxiety disorder symptoms. Journal of Adolescence, 29, 407-417.

*Hale, W.W. III, Raaijmakers, Q., Muris, P., \& Meeus, W. (2005). Psychometric properties of the Screen for Child Anxiety Related Emotional Disorders (SCARED) in the general adolescent population. Journal of the American Academy of Child and Adolescent Psychiatry, 44, 283290.

Hale, W.W. III, Raaijmakers, Q., Muris, P., Van Hoof, A., \& Meeus, W. (2008). Developmental trajectories of adolescent anxiety disorder symptoms: A 5-year prospective community study. Journal of the American Academy of Child and Adolescent Psychiatry, 47, 556-564.

Li, H., Ang, R.P., \& Lee, J. (2008). Anxieties in mainland Chinese and Singapore Chinese adolescents in comparison with the American norm. Journal of Adolescence, 31, 583-594.

Lipsey, M.W., \& Wilson, D.B. (2001). Practical meta-analysis. Thousand Oaks, CA: Sage.

March, J.S., Parker, J.D., Sullivan, K., Stallings, P., \& Conners, C.K. (1997). The Multidimensional Anxiety Scale for Children (MASC): Factor structure, reliability, and validity. Journal of the American Academy of Child and Adolescent Psychiatry, 36, 554-565.

*Monga, S., Birmaher, B., Chiappetta, L., Brent, D., Kaufman, J., Bridge, J., \& Culley, M. (2000). Screen for Child Anxiety Related Emotional Disorders (SCARED): Convergent and divergent validity. Depression and Anxiety, 12, 85-91.

*Muris, P., Dreessen, L., Bögels, S., Weckx, M., \& van Melick, M. (2004). A questionnaire for screening a broad range of DSM-defined anxiety disorder symptoms in clinically referred children and adolescents. Journal of Child Psychology and Psychiatry, 45, 813-820.

Muris, P., Gadet, B., Moulaert, V., \& Merckelbach, H. (1998). Correlations between two multidimensional anxiety scales for children. Perceptual and Motor Skills, 87, 269-270.

*Muris, P., Loxton, H., Neumann, A., du Plessis, M., King, N., \& Ollendick, T. (2006). DSM-defined anxiety disorders symptoms in South African youths: Their assessment and relationship with perceived parental rearing behaviors. Behaviour Research and Therapy, 44, 883896.

*Muris, P., Merckelbach, H., van Brakel, A., \& Mayer, B. (1999b). The revised version of the Screen for Child Anxiety Related Emotional Disorders (SCARED-R): Further evidence for its reliability and validity. Anxiety, Stress and Coping, 12, 411-425.

*Muris, P., Merckelbach, H., van Brakel, A., Mayer, B., \& van Dongen, L. (1998b). The Screen for Child Anxiety Related Emotional Disorders (SCARED): Relationship with anxiety and depression in normal children. Personality and Individual Differences, 24, 451-456.

*Muris, P., Merckelbach, H., Kindt, M., Bögels, S., Dreessen, L., van Dorp, C., Habets, A., Rosmuller, S., \& Snieder, N. (2001a). The utility of Screen for Child Anxiety Related Emotional Disorders (SCARED) as a tool for identifying children at high risk for prevalent anxiety disorders. Anxiety, Stress and Coping, 14, 265283.

*Muris, P., Merckelbach, H., Mayer, B., van Brakel, A., Thissen, S., Moulaert, V., \& Gadet, B. (1998a). The Screen for Child Anxiety Related Emotional Disorders (SCARED) and traditional childhood anxiety measures. Journal of Behavior Therapy and Experimental Psychiatry, 29, 327-339.

Muris, P., Merckelbach, H., Mayer, B., \& Prins, E. (2000). How serious are common childhood fears? Behaviour Research and Therapy, 38, 217-228.

*Muris, P., Merckelbach, H., Ollendick, T., King, N., \& Bogie, N. (2002a). Three traditional and three new childhood anxiety questionnaires: Their reliability and validity in a normal adolescent sample. Behaviour Research and Therapy, 40, 753-772.

*Muris, P., Merckelbach, H., Schmidt, H., \& Mayer, B. (1999a). The revised version of the Screen for Child Anxiety Related Emotional Disorders (SCARED-R): 
Factor structure in normal children. Personality and Individual Differences, 26, 99-112.

*Muris, P., Schmidt, H., Engelbrecht, P., \& Perold, M. (2002b). DSM-IV-defined anxiety disorder symptoms in South African children. Journal of the American Academy of Child and Adolescent Psychiatry, 41, 13601368.

*Muris, P., \& Steerneman, P. (2001b). The Revised version of the Screen for Child Anxiety Related Emotional Disorders (SCARED-R): First evidence for its reliability and validity in a clinical sample. British Journal of Clinical Psychology, 40, 35-44.

Myers, K., \& Winters, N.C. (2002). Ten-year review of rating scales. II: Scales for internalizing disorders Journal of the American Academy of Child and Adolescent Psychiatry, 41, 634-659.

*Ogliari, A., Citterio, A., Zanoni, A., Fagnani, C., Patriarca, V., Cirrincione, R., Stazi, M.A., \& Battaglia, M. (2006). Genetic and environmental influences on anxiety dimensions in Italian twins evaluated with the SCARED questionnaire. Journal of Anxiety Disorders, 20, 760777.

Ollendick, T.H., \& King, N.J. (1994). Fears and their level of inference in adolescents. Behaviour Research and Therapy, 32, 635-638.

Rapee, R.M. (1991). Generalized anxiety disorder: A review of clinical features and theoretic concepts. Clinical Psychology Review, 11, 419-440.

Rapee, R.M. (2001). The development of generalized anxiety. In M.W. Vasey, \& M.R. Dadds, (Eds), The developmental psychopathology of anxiety (pp. 481-503). London: Oxford University Press.

Rodriguez, M.C., \& Maeda, Y. (2006). Meta-analysis of coefficient alpha. Psychological Methods, 11, 306-322.

Rosenthal, R. (1979). The 'file drawer problem' and tolerance for null results. Psychological Bulletin, 86, 638641.
Rothstein, H.R., Sutton, A.J., \& Borenstein, M. (2005). Publication bias in meta-analysis. Chichester: John Wiley \& Sons.

Seligman, L.D., Ollendick, T.H., Langley, A.K., \& Bechtoldt-Baldacci, H. (2004). The utility of measures of child and adolescent anxiety: A meta-analytic review of the Revised Children's Manifest Anxiety Scale, the StateTrait Anxiety Inventory for Children, and the Child Behavior Checklist. Journal of Clinical Child and Adolescent Psychology, 33, 557-565.

${ }^{*} \mathrm{Su}$, L., Wang, K., Fan, F., Su, Y., \& Gao, X. (2008). Reliability and validity of the Screen for Child Anxiety Related Emotional Disorders (SCARED) in Chinese children. Journal of Anxiety Disorders, 22, 612-621.

Varela, R.E., Sanchez-Sosa, J.J., Biggs, B.K., \& Luis, T.M. (2008). Anxiety symptoms and fears in Hispanic and European American children: Cross-cultural measurement equivalence. Journal of Psychopathology and Behavior Assessment, 30, 132-145.

Wang, K., Su, L., Zhu, Y., Qu, J., Yang, Z., \& Zhang, J. (2002). Chinese urban norms of the Screen for Child Anxiety Related Emotional Disorders. Chinese Journal of Clinical Psychology, 10, 270-272.

*Wren, F.J., Bridge, J.A., \& Birmaher, B. (2004). Screening for childhood anxiety symptoms in primary care: Integrating child and parent reports. Journal of the American Academy of Child and Adolescent Psychiatry, 43, 13641371.

*Wren, F.J., Berg, E.A., Heiden, L.A., Kinnamon, C.J., Ohlson, L.A., Bridge, J.A., Birmaher, B., \& Bernal, M.P. (2007). Childhood anxiety in a diverse primary care population: Parent-child reports, ethnicity and SCARED factor structure. Journal of the American Academy of Child and Adolescent Psychiatry, 46, 332-340.

Manuscript accepted 25 May 2010 